\title{
Critical Thinking Concept Reconstructed
}

\author{
Mary Kennedy Minter, Ed.D., Educational Consultant, USA
}

\begin{abstract}
This paper explores the proposition that teaching of critical thinking (CT) should include: (1) identifying and addressing the many environmental variables acting as barriers to our human thinking, i.e., an open system approach, and (2) utilizing the interrelatedness of the CT building blocks, i.e., creative thinking techniques, levels of learning, hierarchy of human needs, classic problem solving processes, and classic logical reasoning.
\end{abstract}

Keywords: Critical thinking definitions, processes of problem solving, creative thinking, logical reasoning, concepts of levels of learning, and open system approach.

\section{INTRODUCTION}

he proposition for this paper is that the concept of "critical thinking" (CT) needs to be analyzed and reconstructed semantically in order to be viable as a strategic learning objective. The term, "critical thinking" can be misleading and ineffective unless the concept is defined and explained by encompassing historically-based building blocks and interdependencies involved in the human thinking process. It seems to this author that the term, "critical thinking," has become "academic jargon" and has evolved to an ineffective umbrella term to subjugate the classic building blocks used as grounded foundations for effective thinking.

The major "building blocks" to the thinking process that will be explored within this paper as interrelated with "critical thinking" $(\mathrm{CT})$ are:

1. Creative problem solving/thinking (CPS)

2. "Open system" concept as a perspective for the thinking/learning process

3. Bloom's Taxonomy (Levels of learning) [related to Maslow's Hierarchy]

4. Classic problem solving process

5. Logic (reasoning)

The CT concept will be defined/discussed concurrently with the other building blocks listed above to demonstrate the inter-relatedness of the learning concepts. As an overall definition to use as a starting point, CT can be defined as:

“. . reasonably and reflectively deciding what to believe or do." ...making reasoned judgments. Basically, it is using criteria to judge the quality of something, from cooking to a conclusion of a research paper. In essence, critical thinking is a disciplined manner that a person uses to assess the validity of something: a statement, news story, argument, research, etc." [Robert Ennis, and paraphrase of Barry Beyer ${ }^{1}$

\section{CREATIVE PROBLEM SOLVING/THINKING (CPS) RELATED TO CT}

The author has elected to start a "reconstruction" of the "critical thinking" (CT) concept with a CPS approach. Creative thinking is needed to view CT from new perspectives, that is, from a lateral thinking view in which to generate different ways to picture a subject.

As an academic model for creative problem solving, CPS was proposed over 50 years ago (e.g., Osborn, 1952). Since then, CPS has become a standard addition to the classic problem solving models and training processes. In the 1980 's, academic variations emerged for CPS. The most important pre-requisite component of 
CPS for this paper's purpose of analyzing CT is "task appraisal." According to the Hillis and Puccio's (1999) analysis of CPS literature, the creative thinking processes involve understanding of "metacognition."

"Metacognition has been described in two ways: 'knowledge about cognition' and 'regulation of cognition.' Knowledge about cognition refers to stable and statable information about one's own or someone else's cognitive processes. Regulation of cognition refers to the planning, monitoring, and checking activities necessary to orchestrate cognition.' (Slife, Weiss \& Bell, 1985, p.437)

With this definition in mind, . . a discussion of Task Appraisal includes four elements: (a) personal orientation, (b) desired outcomes, (c) situational outlook, and (d) CPS methodology (Isaksen, et. al., 1994) ${ }^{2}$ [emphases added]

The above references to CPS represent a starting point for reconstructing our mental view of CT. First, teachers approaching the difficult task of training students in CT must take the time to prepare students for such a task. This paper emphasizes the first three components of "task appraisal:"

(1) personal orientation - e.g., explaining the open system concept to students and having them complete selfassessments of attitudes, behavior, learning and listening styles, etc.

(2) desired outcomes - e.g., specific learning objectives depending on discipline

(3) situational outlook - e.g., assessing background and present environments surrounding the task of creative thinking (permeable boundaries).

\section{CREATIVE THINKING RELATED TO "SYNERGY" AND CT:}

"Not everything that counts can be counted and not everything that can be counted counts." (A. Einstein) ${ }^{3}$ Synergy ("interactions of people or conditions such that the total effect is greater than the sum of the individual effects") 4 may "not be easily counted," but it is very significant at revealing insights needed for "critical thinking." For this author, classroom synergy (or a result of a creative flow of ideas) can be the most enjoyable, enlightening, and profitable learning experience for both students and teachers. This ambiguous, "intellectual force" may not be able to be "measured" with standard statistical methods, but it can be "felt" or "sensed" by participants and unmeasurable, pleasurable learning can take place. For example, students experience those wonderful "a-hah" moments and may actually verbalize out loud a "oh, I got it." It is at that time, as a teacher, you feel good because you know you've worked through a problem with students and together, you have reached the best solution possible given the information available at that time.

Support for this kind of holistic approach to critical thinking is not a new perspective. According to W.J. McKeachie (1988), research in teaching critical thinking should stress:

“. . explicitness, multiple opportunities to practice in differing contexts, and emphasis on developing student selfawareness and self-assessment." [emphasis added] NCRIPTAL (National Center for Research to Improve Postsecondary Teaching and Learning) research in teaching CT indicates the use of multiple combinations of thinking concepts may be the best approach, e.g., a combination of traditional problem solving methods, logic, and creative thinking. Above all, the environment is a key factor:

"We [NCRIPTAL] conclude that at least three elements of teaching seem to make a difference in student gains in thinking skills: (1) student discussion, (2) explicit emphasis on problem solving procedures and methods using varied examples, and verbalization of methods and strategies to encourage development of metacognition. Because productive thinking involves knowledge, it seems likely that this kind of teaching is likely to be most effective in the context of subject-matter courses. ${ }^{, 6}$

\section{THE OPEN SYSTEM CONCEPT RELATED TO CT}

The above discussion of creative thinking leads to this author's contention that the open system concept can represent a creative camera angle with which to view critical thinking. For example, from a 1990's viewpoint, Peter Senge emphasized that the art and practice of viewing organizations (e.g., the classroom environment) as an open 
system necessitates a shift of mind (metanoia) by acquiring the attitude that organizations (the classroom) are continually learning (changing). Senge proposed that the open system model allows the "seeing of the forest and the trees," that is, it provides a wide-angle lens that can view the larger dimensions and still capture the details. ${ }^{7}$

If there can be agreement that the concepts discussed in this paper are inter-related and inter-dependent and that the open system viewpoint can be used to facilitate awareness of input and environmental factors affecting "critical thinking" (CT) as a learning objective, then perhaps teachers and students can progress closer to an ideal of the process.

In order to relate the open system concept to the building blocks of CT, a brief explanation of the open system is needed. The key components of the open system concept are: "input, process, output, permeable boundaries, and feedback." This concept forces us to consider the many variables that affect the dynamic and interdependent teaching/learning process, including "critical thinking." For example, "inputs" include, but are not limited to: students and teachers (their backgrounds encompassing culture, health, education, experiences, skills, attitudes/behaviors, and interpersonal relationships coming into the classroom learning environment). Key components of input are: (1) the teacher's expertise in subject matter, instructional management and communication within the classroom setting and (2) the student's readiness to learn (basic skills, e.g., reading, writing, math and attitude/behavior/health factors).

The environment of the college/university and classroom is part of the "permeable boundaries" (i.e., How do the relevant environmental factors affect the learning process?). The following are examples of permeable boundary factors affecting both students and teachers: the "state of the country (e.g., economy, war, threats, etc.) including the "state of the immediate community environment" (e.g., economy, threats of violence, school facilities), and family environment (e.g. family-related economy, family support, physical/mental status, and educational support factors).

Within the "formal organizational structure" of the classroom, the important process of "resource conversion" takes place. This represents the crucial stage in the "conversion" of information dissemination management (teachers and students) and information transplanting, managing, and storage (by students and teachers). However, the conversion stage is greatly effected by the permeable boundaries (environmental) factors.

Critical parts of the open system concept, as it relates to education, are the "outputs" and "feedback." A key "output" is proof that students have learned, at various levels of learning, the subject matter and skills transmitted during the conversion stage. A key feedback factor is the kind of assessments used that help to prove learning has actually taken place or that skills have been acquired and can be executed effectively. "Feedback" is needed through testing, practice, and other evaluation methods to document the results that can aid students and teacher to improve the education process.

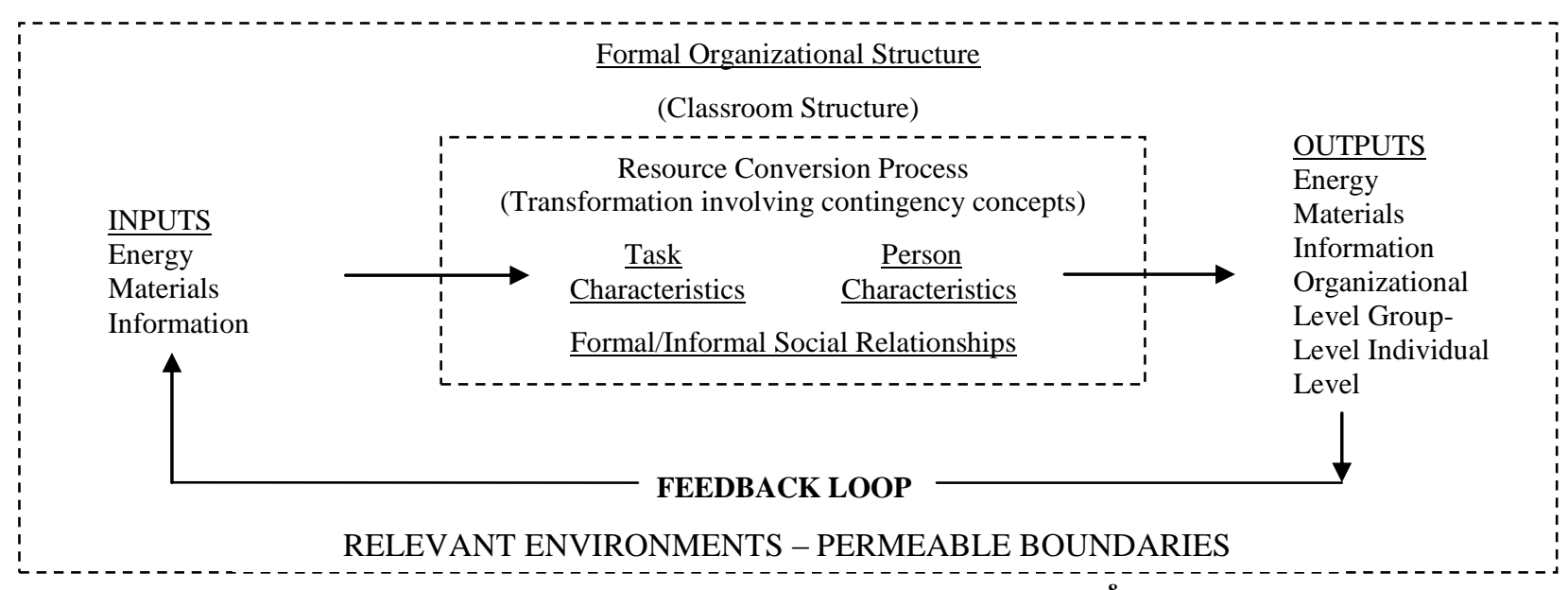

Figure 1: Adapted model of an open system concept ${ }^{8}$ 
How are teachers to define basic learning concepts to demonstrate that learning of these fundamental processes has taken place within the students we have allegedly taught? In order to improve quality of assessments, teacher need to carefully define and delineate what processes they are attempting to teach, i.e., levels of learning, problem solving, creative thinking and critical thinking.

\section{BLOOM'S TAXONOMY OF LEARNING/THINKING RELATED TO CT}

In education, teachers tend to emphasize the Bloom's cognitive domain; unfortunately, the focus often occurs at the lowest level of learning — knowledge and comprehension. These levels of learning are important as "building blocks," but if they become the only levels of assessing learning (e.g., the multiple choice test), then students are not coming close to acquiring a "critical thinking" level of learning. According to Bloom's higher levels of learning, teachers must lead their students through the processes of application, analysis, synthesis, and evaluation. These levels of learning are inherent in the concepts of problem solving, creative thinking, logic (reasoning) and $C T$ that need to be included in the open system conversion stage.

In the 1960's, Bloom's Committee of colleges published their taxonomy based on research and development of education learning objectives (two volumes: The Affective Domain and Cognitive Domain). The Psychomotor Domain was never completed in detail due to a change in committee structure. In the past 50 years, this taxonomy model has become a classic paradigm for assessing levels of learning, not just at the college level, but all levels of USA education. Fortunately, other significant research has been done in the affective and psychomotor domain to apply to sports, drama, music, et.al. (2) For example, the Affective and Psychomotor Domains have been outlined as follows:

$\begin{array}{lll}\text { Affective Domain } & & \text { Psychomotor Domain } \\ \text { Characterization } & \text { (Highest) } & \text { Nondiscursive Communication } \\ \text { Organization } & & \text { Skilled movements } \\ \text { Valuing } & & \text { Physical Abilities } \\ \text { Responding } & & \text { Perceptual Abilities } \\ \text { Receiving } & \text { (Lowest) } & \text { Basic-Fundamental Movements } \\ & & \text { Reflex Movements }\end{array}$

Beyond Bloom-Multiple Intelligence:

The research of different kinds of human intelligence has also added to the affective and psychomotor domains, e.g., Goleman's "Emotional and Social Intelligence." Goleman defines "Emotional Intelligence" as human abilities that include self-awareness that leads to "... . self control, zeal and persistence, and the ability to motivate oneself. And these skills . . .can be taught to children, giving them a better chance to use whatever intellectual potential the genetic lottery may have given them." "10 [emphasis added] Regarding "Social Intelligence," Goleman proposes the principle that our social aptitude is ". . . acting wisely in human relationship. . . . we can take the measure of a relationship in terms of a person's impact on us, and ours on them." "How do these concepts of emotional and social intelligence relate to thinking skills within the classroom environment? Basically, they relate to the human inputs and permeable boundary factors which students and teachers bring into the learning conversion stage of the open system process.

Goleman's $21^{\text {st }}$ century contribution to the "human intelligence" research is grounded on the $20^{\text {th }}$ century research dealing with different approaches to human intelligence, such as:

1. Edward Thorndike (1920)_-"IQ" testing

2. David Wechsler (1950's) - “IQ" testing refined

3. J.P. Guilford (1960's) - 120 separate intellectual abilities

4. Robert Sternberg (1985) - "successful intelligence"

5. Howard Gardner (1993) - multiple intelligences ${ }^{12}$ 
For this author, Gardner represents an enlightening extension of the current Goleman's approach. Gardner's 1983 theory proposed an initial list of seven (7) "personal intelligences": Linguistic, Logical-mathematical, Musical, Bodily-kinesthetic, Spatial, Interpersonal, Intrapersonal. Since his initial list, he has added others for continued study: Naturalist, Spiritual, Existential, and Moral. Although Gardner's work is criticized for lack of empirical evidence, his proposals represent a heuristic approach to the study of multiple human intelligences that have encouraged educationists to look beyond a narrow intelligence view. This wide angle lens approach to how the human brain works supports the need for an open systems approach to learning and practicing critical thinking. ${ }^{13}$

These intelligence factors, along with the domains of learning, converge to affect the total learning environment. This author contends that ultimately, students (and teachers) have to assume their own responsibility for self control, motivation, and persistence (emotional/intrapersonal intelligence) and acting wisely in human relationships (social/interpersonal intelligence). These personal attributes and behaviors can be encouraged in a school setting that provides a supportive and controlled environment. However, the basic responsibility for nurturing social and emotional intelligence remains within the parents and students with the support of teachers. These basic intelligence factors and behaviors are also inherent in Maslow's Hierarchy of Human Needs theory as discussed below.

If, according to Goleman, et.al., these emotional and social intelligence skills can be taught, this author contends that students (and teachers) must become aware of and analyze the myriad of outside influences affecting the learning parameters within the classroom, i.e., permeable boundaries of the open system analysis. For example, more classroom time needs to be directed to helping students think through the environmental issues that they face every day. This analysis process can provide insight into student (and teacher) biases, hardships and help to overcome counter-productive interrelationships. Subject matter of a course can be incorporated throughout this selfassessment/awareness process; however, a good starting point is to engage in CT regarding current mass media communication, especially news broadcasting. Current, major USA issues provide ample opportunities to practice CT by analyzing and "making reasoned judgments" based on an assessment of the validity of "facts" presented, for example: national health program legislation, terrorist threats and reactions, national/international economics and the state of USA infrastructures, public school conditions.

\section{Bloom's Taxonomy related to Maslow's Hierarchy of Needs:}

In comparing Maslow's Hierarchy of Needs to Bloom's Taxonomy of Learning, the author is attempting a "creative thinking" process by suggesting a synthesis of the two paradigms - one dealing with the levels of human needs and the other, levels of human learning. How is this comparison relevant to critical thinking? If one accepts the assumption that the levels-of-learning concept is a building block for "critical thinking," and if Maslow's Need Hierarchy can be compared to levels of learning, then our learning processes (including "critical thinking") are relevant to meeting our innate human needs.

It seems obvious to this learner that Bloom's three domains (cognitive, affective, psychomotor) of learning are related to Maslow's levels of needs. For example, certainly the cognitive levels of learning apply as humans work their way from the lowest to highest levels of the human need hierarchy. The author believes that the highest level of need, "self-actualization," and the highest levels of learning (synthesis, evaluation, judgment) are crucial to the process of life-long learning. That is, the process of learning never ends and a teacher should emphasize that concept to students as they begin their life-long journey through these many stages of "self-actualization."

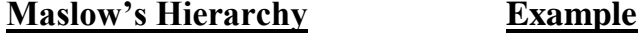

Physical needs----------------

Safety

Belonging "potty training" crossing streets formal schooling
Bloom's Taxonomy (cognitive, affective, psychomotor) All three domains can relate to each example; only samples are listed.

all three domains

knowledge, comprehension

application (socializing) 

Esteem needs
obtaining a positive self- perception and
self-analysis--identifying
independence
good/bad, right from wrong
Cognitive needs
involvement in
higher levels of learning
(synthesis-developing cognitive
interests and combining subject
learning (formal and informal)
Aesthetics
perceiving an order
in things, but retaining all three domains
creativity
Self-actualization --------- $\quad$ realizing potential
on-going process of merging synthesis, evaluation, judgment experiences

\section{CLASSIC PROBLEM SOLVING RELATED TO CT}

Another pedagogical building block that is inherent in "critical thinking" is the classic problem-solving process. If one accepts a basic definition that critical thinking means making reasoned judgments, then the process of critical thinking would logically include the classic problem-solving format.

Classic problem-solving format (standard steps)

Standard steps for problem solving include:

1. define the problem, including differentiate fact from opinion, identify causes, determine whose problem it is, avoid stating the problem as a solution;

2. generate alternative solutions;

3. evaluate and select the best solution, given the information available;

4. implement and follow up on the solution. ${ }^{14}$

The classic problem-solving format is basic in our pedagogy; for example, John Dewey emphasized a logic-based approach to problem-solving (critical thinking) in 1938 when he discussed, Logic: The Theory of Inquiry. He proposed a six-step process:

1. "our recognition of [a] situation as a problem to which the principles of inquiry may be applied."

2. "our invention of various hypotheses as potential solutions that might (if viable) resolve the problem,"

3. "our careful reasoning about the meaning of these solutions in relation to the problem itself and to our other convictions,"

4. "the application of our results to the facts of the situation, understood by reference to the operation of our observations on the, and"

5. "acceptance of a scientific or common-sense explanation of the situation that provisionally reduces the original indeterminacy."

"Notice that at every stage of this process, Dewey emphasized the dynamic and tentative character of our knowledge of the world." 15 [emphases supplied]

Throughout academic discussion of the problem-solving process is the caveat that participants usually have incomplete information on which to analyze alleged problems and solutions; therefore, the process is inherently fallible. Perhaps this fallibility has led educators to the jargon-filled version of "critical thinking" as a preferred approach. However, no amount of jargonizing and word play will diminish the fact that humans face problem 
analysis and solutions with incomplete information.

\section{LOGIC PRINCIPLES RELATED TO CT}

Ironically, the "critical thinking" process proposes to enhance the classic problem solving method by emphasizing the need for logical reasoning. Utilizing logic is certainly not a new approach to classic problem solving. The "scientific method" of problem analysis and the warnings of fallacious logic/reasoning have been standard building blocks for educators. However, the current academic concept of "critical thinking" proposes to go beyond the classic basics of problem-solving and logical reasoning. It is fascinating to review the many CT definitions; the following is the most inclusive explanation that this author found and it certainly makes clear the essence of "CT" as a concept is founded on logic principles. For those of us who were college trained in the old school of classic Greek-based logic (argumentation and debate), the jargon of "CT" represents an attempt to apply a $21^{\text {st }}$ century costume on the classic Greek forms of logic.

Peter Facione's essay on "Critical Thinking: What It Is and Why It Counts" proposes a consensus statement (of experts in the field):

[The essay] ‘. .takes a Socratic approach to defining critical thinking. . .We understand critical thinking to be purposeful, self-regulatory judgment which results in interpretation, analysis, evaluation, and inference, as well as explanation of the evidential, conceptual, methodological, criteriological, or contextual considerations upon which judgment is based. [Since this includes almost all types of logical reasoning,] CT is essential as a tool of inquiry. . . While not synonymous with good thinking, $C T$ is a pervasive and self-rectifying human phenomenon. The ideal critical thinker is habitually inquisitive, well-informed, trustful of reason, open-minded, flexible, fair-minded in evaluation, honest in facing personal biases, prudent in making judgments, willing to reconsider, clear about issues, orderly in complex matters, diligent in seeking relevant information, reasonable in selection of criteria, focused in inquiry, and persistent in seeking results which are as precise as the subject and the circumstance of inquiry permit. CT skills . . . are the basis of a rational and democratic society. "16 [emphases provided]

This author is puzzled by the above statement, "While not synonymous with good thinking. . " If CT is supposed to be the epitome of investigative search for the "truth" through logical reasoning, then why is it not "synonymous with good thinking?" A possible interpretation, by this author, is: CT seems to be a set of skills for attempting the "best" (good) thinking possible given all the inherent variables including incomplete facts/information. Wasn't this the caveat proposed by J. Dewey in his 1938 problem-solving format?

\section{CRITICAL THINKING CONCEPT SUMMARY: (SAMPLE DEFINITIONS OF CT)}

(1) "[Critical thinking is] ... the examination and test of propositions of any kind which are offered for acceptance, in order to find out whether they correspond to reality or not. The critical faculty is a product of education and training. It is a mental habit and power. . . It is our only guarantee against delusion, deception, superstition, and misapprehension of ourselves and our earthly circumstances." 17

"Critical thinking is self-guided, self-disciplined thinking which attempts to reason at the highest level of quality in a fair-minded way. People who think critically consistently attempt to live rationally, reasonably, empathically. ... They avoid thinking simplistically about complicated issues and strive to appropriately consider the rights and needs of relevant others. They recognize the complexities in developing as thinkers, and commit themselves to life-long practice toward self-improvement. They embody the Socratic principle: The unexamined life is not worth living, because they realize that many unexamined lives together result in an uncritical, unjust, dangerous world."18

(3) [Regarding analysis of thinking. . .] "Everyone thinks; it is our nature to do so. But much of our thinking, left to itself, is biased, distorted, partial, uniformed, or downright prejudiced. If we want to think well, we must understand at least the rudiments of thought, the most basic structures out of which all thinking is made. We must learn how to take thinking apart.

thinking:

All thinking is defined by the Eight Elements that make it up. Eight basic structures are present in all 
1. purpose, goal objective

2. question at issue, problem, issue

3. information, data, facts, observations, experiences

4. interpretation and inference, conclusions, solutions

5. concepts, theories, definitions, axioms, laws, principles, models

6. assumptions, presupposition, taking for granted

7. implications and consequences

8. point of view, frame of reference, perspective, orientation. ${ }^{19}$

This last reference on how we think definitely speaks to the role of metacognition in the process of understanding and engaging in CT.

\section{SUMMARY}

\section{$\underline{\text { Permeable boundaries' Effect on "CT" and other building blocks: }}$}

This author proposes that, for critical thinking, not enough emphasis is placed on audience analysis, i.e., self assessments to provide students (and teachers) with usable information about "where they are coming from," e.g., identifying:

1. preferred learning styles

2. inherent biases

3. communication styles

4. listening behaviors and preferences (selective perceptions/frame of references)

5. cognitive preferences for content/subject matter (that is, math, science, or general subjects)

6. environmental issues (e.g., biases, prejudices, distortions, current events)

In order to involve students in the conversion stage of the open system view of acquiring knowledge and skills, a significant degree of audience analysis should be conducted. Teaching methods can then be adapted to better meet the learning needs of the students in a particular content course. One approach that the author has used is to give students a battery of self-assessment surveys at the beginning of a course and to discuss the findings with them before beginning structured "critical thinking" objectives within the course subject matter. The results of self assessments are referred to frequently throughout the course to keep students aware of their personal frames of reference while attempting a valid "thinking" process in whatever format is being used.

This author maintains an optimist's viewpoint that, in a gestalt sense, there can be training of students in "good thinking," alias "critical thinking," if we recognize (identify) and address: (1) the many environmental variables that may be acting as barriers to our human thinking processes, and (2) the interrelatedness of the critical thinking "building blocks," i.e., creative thinking techniques, open system concept, levels of learning, hierarchy of human needs, classic problem solving processes, and logically reasoning.

\section{AUTHOR INFORMATION}

Mary Kennedy Minter, Ed.D., has been a college teacher for over 30 years and specializes in faculty development consulting. She has taught instructional communication and business management at Texas Christian University, U. of Texas, Arlington, Texas Wesleyan University, University of Akron, and Cleveland State University.

Her degrees are: doctorate in Higher Education Administration, U. of Michigan; Master's degree in Organizational Communication/Industrial Relations from Purdue University; and Bachelor of Arts from Ohio University. 


\section{ENDNOTES}

${ }^{1}$ Beyer, Barry \& Ennis, Robert (2009), "Critical thinking Skills in Education and Life," p.1 http://www.asa3.org/ASA/education/think/critical.htm

${ }^{2}$ Hillis, Patrick M. \& Puccio, Gerard J. (1999), "Literature Analysis of the Interdiscipinary Applications of Creative Problem Solving" (Abstract), p.2 http://www.buffalostate.edu/org/cbir/readingroom/html/Hillis-Puccio99.html

${ }^{3}$ Bennion, Donald H., "Bloom's Taxonomy and Critical Thinking Skills," Eastern Michigan University, September 6,2009 (handout), p. 2.

${ }^{4}$ Dictionary: Webster's New World Dictionary ( $3^{\text {rd }}$. Ed.). (1991).

${ }^{5}$ McKeachie, W. J., "Teaching Thinking," (NCRIPTAL) National Center for Research to Improve Postsecondary

Teaching and Learning, September 1988. p.1.

${ }^{6}$ Ibid., p.1

${ }^{7}$ Senge, P.M. (1990). The fifth discipline: The art and practice of the learning organization.

${ }^{8}$ Mitchell, T. R., \& Larson, J. R. (1987) People in organizations: An introduction to organizational behavior $\left(3^{\text {rd }}\right.$. ed.), p. 65.

${ }^{9}$ Bennion, Op.Cit. p. 2.

${ }^{10}$ Goleman, Daniel. (1995). Emotional Intelligence, p.xxi.

${ }^{11}$ Goleman, Daniel. (2006). Social Intelligence, p.12 (quoting Thorndike).

${ }^{12}$ Ibid. p.332.

${ }^{13}$ Gardner, Howard. Ref. "Frames of Mind. The theory of multiple intelligences.

http://www.infed.org/thinkers/garner.htm (pp.3-5;7-8)

${ }^{14}$ Whetten, David A. \& Cameron, Kim S. (1998). Developing Management Skills $\left(4^{\text {th }}\right.$ Ed.). p.144.

${ }^{15}$ Dewey, John. (1938). Logic: the theory of inquiry. http://www.philosophypages.com/hy6e.htm

${ }^{16}$ Facione, Peter, "Critical Thinking: What It Is and Why It Counts."

http://www.asa3.org/ASA/education/think/critical.htm

${ }^{17}$ Sumner, W. G. (1940). Folkways: A Study of the Sociological Importance of Usages, Manners, Customs, Mores, and Morals. pp.632, 633.

${ }^{18}$ Elder, L. (2007)http://www.criticalthinking.org/aboutCT/define crtical thinking.cfm.

${ }^{19} \mathrm{http}$ ://www.criticalthinking.org/CT model1.cfm (copyright: 2007 Foundation for Critical Thinking, from The Thinker's Guide to Analytic Thinking.)

\section{REFERENCES}

1. Foundation for Critical Thinking (2009), P.O. box 220, Dillon Beach, CA 94929

2. Gardner, Howard. (1993). Multiple Intelligences: The theory in practice. New York: Basic Books.

3. Goleman, Daniel. (1995). Emotional Intelligence (Why it can matter more than IQ). New York: Bantam Books.

4. $\quad$ Goleman, Daniel. (2006). Social Intelligence. New York: Bantam Books.

5. Hunsacker, P.L., \& Cook, C.W. (1986). Managing organizational behavior. Reading, MA: AddisonWesley Publishing Company. p. 40.

6. http://www.criticalthinking.org/aboutCT/sumnersDeinitionCT.cfm

7. Mitchell, R. R., \& Larson, J. R. (1987). People in organizations: An introduction to organizational behavior ( $3^{\text {rd }}$.ed.). New York: McGraw-Hill. p. 65.

8. Senge, P. M. (1990; 2006, $2^{\text {nd }}$ ed.). The fifth discipline: The art and practice of the learning organization. New York: Doubleday/Random House, Inc. 


\section{NOTES}

